\title{
IN VITRO EVALUATION OF THE MARGINAL MICROLEAKAGE OF AMALGAM RESTORATIONS ASSOCIATED WITH DENTIN ADHESIVE, GLASS IONOMER CEMENT AND CAVITY VARNISH BY MEANS OF DIFFERENT EVALUATION METHODS
}

\author{
AVALIAÇÃO IN VITRO DA MICROINFILTRAÇÃO MARGINAL EM RESTAURAÇÕES DE \\ AMÁLGAMA ASSOCIADAS A ADESIVO DENTINÁRIO, CIMENTO DE IONÔMERO DE VIDRO \\ E VERNIZ CAVITÁRIO, UTILIZANDO DIFERENTES MÉTODOS DE AVALIAÇÃO
}

Adriano Tomio HOSHIํㅜ, Salete Moura Bonifácio da SILVA², Aymar PAVARINI ${ }^{3}$

\begin{abstract}
1- DDS, MSc, Assistant Professor, Department of Pediatric Dentistry, UNIOESTE, Cascavel - PR.
2- DDS, PhD, Assistant Professor, Department of Pediatric Dentistry, Bauru Dental School - USP.

3- DDS, PhD, Chairman Professor, Department of Pediatric Dentistry, Bauru Dental School - USP.

Corresponding address: Adriano Tomio Hoshi - Al. Octávio Pinheiro Brisolla, 14-29 - Ap. 31 - Cep.: 17012-191

Vila Universitária - Bauru - SP - E-mail: adrhoshi@yahoo.com - Phone Number: (14) 9717-7453 / 224-3704
\end{abstract}

Received: August 28, 2003 - Modification: December 9, 2003 - Accepted: December 15, 2003

\begin{abstract}
$T_{\text {his in vitro study evaluated the marginal microleakage of amalgam restorations associated with the cavity varnish Copalite }}$ - Cooley \& Cooley (GI-CP), dentin adhesive OptiBond Solo - Kerr (GII-OS) and the glass ionomer cement Vitremer - 3M (GIIIVT). Forty-five premolars were employed, which were submitted to independent class II preparations at the mesial and distal aspects comprising the marginal ridges and were restored with Dispersalloy - Dentsply. Afterwards, the teeth were thermocycled and stored in $0.5 \%$ basic fuchsine for 24 hours. The evaluations were conducted on a light microscope with 150x magnification and on the Sigma Scan software with employment of a single line and segmented lines. Data analysis allowed to establish that none of the materials was able to eliminate the marginal microleakage, having the GI - CP presented greater and statistically significant values in relation to the other groups in all evaluation methods $(p<0.05)$. The lowest values were displayed by the GIII-VT, yet with no statistically significant difference when compared to GII-OS, except for the evaluation at the Sigma Scan in single line. The three evaluation methods showed a strong positive relationship to each other.

Uniterms: Dental materials; Marginal microleakage.
\end{abstract}

\begin{abstract}
RESUMO
$E$ ste trabalho avaliou, in vitro, a microinfiltração marginal de restaurações de amálgama associadas ao verniz cavitário Copalite - Cooley \& Cooley (GI - CP), ao adesivo dentinário OptiBond Solo - Kerr (GII - OS) e ao CIV Vitremer - 3M (GIII - VT). Foram utilizados 45 pré-molares que receberam preparos cavitários independentes classe II nas faces mesial e distal, envolvendo as cristas marginais. Todas as cavidades foram restauradas com a liga Dispersalloy - Dentsply. Posteriormente, os dentes sofreram termociclagem e foram armazenados em solução de fucsina básica a 0,5\% por 24 horas. As avaliações foram realizadas através de um microscópio óptico com aumento de 150 vezes e no software Sigma Scan, utilizando linha única e linhas segmentadas. A análise dos dados obtidos permitiu constatar que nenhum dos materiais foi capaz de eliminar a microinfiltração marginal, sendo que o GI - CP apresentou valores maiores e estatisticamente significantes $(\mathrm{p}<0,05)$ em relação aos demais grupos em todos os métodos de avaliação. Os menores valores foram obtidos pelo GIII - VT, porém sem diferença estatisticamente significante quando comparado ao GII - OS, exceto pela avaliação no Sigma Scan em linha única. Os três métodos de avaliação de medidas lineares empregados mostraram ter uma forte correlação positiva entre si.

Unitermos: Materiais dentários; Microinfiltração marginal.
\end{abstract}




\section{INTRODUCTION}

Despite of the advent of esthetic restorative materials for restoration of posterior teeth, the amalgam is still widely used because of its excellent physical properties and low cost, besides the low technique sensitivity ${ }^{10,13,22}$. On the other hand, it also presents failures and limitations such as the color and the lack of adhesion to the dental structure, in addition to the criticisms concerning the toxic effects of mercury ${ }^{11,13,26}$. Another problem is the marginal microleakage, defined as the penetration of oral fluids, bacteria, molecules and ions between the cavity wall and the restorative material ${ }^{9}$, which allows the occurrence of secondary caries and pulp irritation, besides the reduction in the restoration longevity ${ }^{4,11,27}$. However, the amalgam is the only restorative material that increases the marginal sealing along time, by means of the deposit of products originated from its own corrosion in the interface between tooth and restoration ${ }^{4,5,22}$.

The application of cavity varnish became a routine procedure with a view to prevent the early marginal microleakage while the deposit of corrosion products does not occur ${ }^{4,24,27}$. In 1986, Varga, Matsumura, Masuhara ${ }^{28}$ reported a new technique that associated the dentin adhesive to amalgam in order to enhance the bond strength and reduce the marginal microleakage. Several in vitro studies ${ }^{4,5,11,15}$ have demonstrated that the adhesives really reduce the microleakage when compared to the varnish. Currently, there are one bottle adhesives on which the primer and adhesive are combined in the same bottle. Researches ${ }^{12,17}$ have been demonstrating that these materials allow marginal microleakage within a similar depth as the oldest adhesive systems. One of such materials is the Optbond Solo, mainly constituted by BIS-GMA, HEMA and approximately 25\% of fillers, which, according to the manufacturer, releases fluoride and is designed for utilization with resin, metals, amalgam and ceramics.

Another material that has been used in combination with amalgam is the glass ionomer cement (GIC) 2,19,21,23, which plays an important role in the prevention of secondary caries, especially because of the release of fluoride ions. Concerning the resin modified glass ionomer cements (RMGIC) like the VITREMER, there are the further advantages of the control of the working time by means of the incorporation of a lightcured resin component $\mathrm{t}^{1,8,16,18}$, lower sensitivity to dehydration and moisture ${ }^{8,18}$, lower solubility and higher bond strength to the dental structure ${ }^{16}$.

Due to the evolution of the techniques and restorative materials, the initial accomplishment of in vitro evaluations is important to provide an overview of its behavior in vivo. Therefore, investigation of the association between amalgam and different intermediate materials can improve the quality of a relatively simple restorative technique of a reasonable cost and wide clinical application. The aim of this study was to evaluate the marginal microleakage of amalgam restorations in combination with a dental adhesive, a RMGIC and a cavity varnish, using three different methods for quantitative evaluation.

\section{MATERIALS AND METHODS}

A total of 45 human intact premolars were employed, which were submitted to two independent class II cavity preparations, at the mesial and distal aspects, comprising the occlusal ridges, adding up to 90 cavities. The preparations were accomplished with carbide bur \# 245 and standardized dimensions of $4.0 \mathrm{~mm} \pm 0.2 \mathrm{~mm}$ of buccolingual diameter and $1.5 \mathrm{~mm}$ of depth at the cervical wall, extending up to $1 \mathrm{~mm}$ beyond the cementoenamel junction.

The mesial and distal preparations of the same tooth were protected with different materials so that the variable tooth could be excluded, adding up to 30 restorations for each group. The cavity varnish COPALITE - Cooley \& Cooley, Houston, TX, USA (GI-CP) was employed as a control, while the dental adhesive OPTIBOND SOLO - Kerr Corporation, Orange, CA, USA (GII-OS) and the RMGIC VITREMER - 3M Dental Products, St. Paul, MN, USA (GIIIVT) were the materials tested.

All materials were applied according to the manufacturers' recommendations, except for the RMGIC that, after application of the primer, was prepared in a proportion of $1 / 4$ of the powder measure to 1 drop of liquid. A thin coat of the material was applied on all walls, and the amalgam was immediately condensed with the RMGIC while on the plastic phase.

All cavities were restored with DISPERSALLOY Dentsply, Milford, DE, USA, a dispersed phase alloy enriched by copper, associated to K DENT mercury Quimidrol, SC, Brazil, in a 1:1 ratio. For GIII-VT, light curing was accomplished for 40 seconds on the occlusal surface and further 40 seconds on the proximal aspect. The teeth were stored in deionized water at $37^{\circ} \mathrm{C}$ for 24 hours and after that period the tooth surface was isolated with two layers of nail polisher up to $1 \mathrm{~mm}$ from the restoration. The teeth were submitted to thermocycling in deionized water at $5^{\circ} \mathrm{C} \pm 4^{\circ} \mathrm{C}$ and $55^{\circ} \mathrm{C} \pm 4^{\circ} \mathrm{C}$ up to 500 cycles with baths of 15 seconds, and then stored in $0.5 \%$ aqueous solution of basic fuchsine for 24 hours at $37^{\circ} \mathrm{C}$. The teeth were washed in tap water for 24 hours for removal of the excess dye at the surface.

The teeth were sectioned in mesio-distal direction, yielding approximately four $1.0 \mathrm{~mm}$ slices for each tooth. Evaluation of the marginal microleakage was performed in both aspects of each slice, through three different methods for the achievement of linear measures (mm): light microscope (MITUTOYO TM-505, Japan) with 150x magnification and two digitized methods, known as Sigma Unique Line (SUL) and Sigma Segmented Lines (SSL), using the software Sigma Scan 2.0 (Jandel Corporation) with 4x magnification. After capture of the images with a scanner, a single straight line was traced in the SUL method from the cavosurface angle of the cavity up to the point of maximum penetration of the dye. In the SSL method segmented lines were defined on the entire extension of dye penetration, following possible irregularities on the cervical and axial walls.

Three readings of each specimen for each method were performed in different moments by a calibrated examiner. 
The data were analyzed by means of the ANOVA test and the Tukey test for multiple comparisons $(\mathrm{p}<0.05)$. Pearson's Correlation test was employed for the evaluation methods.

\section{RESULTS}

Considering both sides of each slice, a total of 184 specimens were obtained for GI-CP, 202 for GII-OS and 196 for GIII-VT. The results for each group according to the evaluation method are presented in Table 1.

The ANOVA statistical test was performed using the means of marginal microleakage of the groups for each evaluation method separately, and between the evaluation methods considering each group separately. Since there was a statistically significant difference between the study groups and between the evaluation methods, the Tukey test for multiple comparisons was applied at a significance level of $5 \%$ in both tests.

Table 2 presents the results of the correlation between the three evaluation methods considering all restorations performed. It may be observed that, despite of the differences existing in the means of evaluation, the methods employed presented the same pattern of results in the different groups, as demonstrated by the strong positive correlation found.

\section{DISCUSSION}

Several materials have been suggested to reduce the marginal microleakage, and because of this large diversity, the present study aimed at evaluating a cavity varnish, a dentin adhesive and a RMGIC.

Table 1 demonstrates that GI-CP presented the highest values of dye penetration in all evaluation methods, with statistically significant differences compared to the other groups. Even though it was not the aim of the present study, it was also observed that the specimens restored with cavity varnish exhibited dye penetration in the dentinal tubules quite frequently. According to Ben-Amar ${ }^{5}$ and Olmez, Cula, Ulusu $^{20}$, this probably occurs because the cavity varnish is a hydrophobic and porous material that cannot be bonded to the amalgam and the dental structure, producing only a mechanical sealing.

A remarkable reduction in marginal microleakage was observed for GII-OS compared to GI-CP, as demonstrated in Table 1, in agreement with other studies ${ }^{5,6,27}$. The light-cured one bottle adhesive system employed is constituted by a hydrophilic solution that penetrates the etched dental structure, allowing the development of resin tags ${ }^{14}$. Since it has approximately $25 \%$ of inorganic fillers, there may be some improvement in its resistance to the masticatory efforts when clinically applied, because it would act as an elastic coat able to absorb the functional stresses concentrated at the adhesive interface, preserving the union between the dental structure and the restorative material ${ }^{7}$.

The GIII-VT presented the best performance in this study

TABLE 1- Mean and standard deviation of the marginal microleakage $(\mathrm{mm})$ observed on the study groups, obtained by means of the three evaluation methods

\section{EVALUATION METHODS}

\begin{tabular}{llll}
\hline GROUP & MICROSCOPE & SUL & SSL \\
\hline GI-CP & $1.101_{\mathrm{a}}{ }^{\star} \pm 0.379$ & $0.763_{\mathrm{a}}{ }^{\star} \pm 0.371$ & $1.183_{\mathrm{a}}{ }^{\star} \pm 0.944$ \\
GII-OS & $0.585_{\mathrm{b}}{ }^{\star} \pm 0.355$ & $0.470_{\mathrm{a}} \pm 0.313$ & $0.592_{\mathrm{b}}{ }^{\star} \pm 0.559$ \\
GIII-VT & $0.409_{\mathrm{b}}{ }^{\star} \pm 0.198$ & $0.275_{\mathrm{a}}{ }^{\star} \pm 0.108$ & $0.293_{\mathrm{b}}{ }^{\star} \pm 0.110$ \\
\hline
\end{tabular}

Considering each evaluation method separately, groups with the same letter have no statistically significant differences to each other.

Considering each group separately, evaluation methods with the same symbol have no statistically significant differences to each other.

TABLE 2- Parameters of the Pearson's Correlation between the evaluation methods

\begin{tabular}{lccccc}
\hline COMPARISONS & $\mathrm{R}$ & $\mathrm{r}^{2}$ & $\mathrm{~T}$ & $\mathrm{P}$ & $\mathrm{n}$ \\
\hline Microscope x SUL & $0.909^{*}$ & 0.827 & 20.485 & 0.000 & 90 \\
Microscope x SSL & $0.838^{\star}$ & 0.702 & 14.404 & 0.000 & 90 \\
SUL x SSL & $0.915^{\star}$ & 0.838 & 21.311 & 0.000 & 90 \\
\hline
\end{tabular}

* strong positive correlation $(\mathrm{R}>0.75)$ 
(Table 1), corroborating the results of other authors, who observed that the application of RMGIC reduced the marginal microleakage of amalgam restorations when compared to the cavity varnish ${ }^{21,23}$ or adhesive system ${ }^{23}$. Despite of the positive results achieved by the RMGIC, it was not statistically superior to GII-OS in all evaluation methods, except for the SUL method, as presented in Table 1. More uniform results could also be observed for the RMGIC when compared to the other materials, especially on the evaluations employing digitized images. Even though the powder:liquid ratio may influence the physical properties of the material, this procedure comprised the achievement of a more fluid mixture that could be applied on the cavity walls more easily and homogeneously. Besides this study, others have employed the same RMGIC to accomplish amalgam restorations ${ }^{18,23}$, yet following the manufacturer's instructions, with a 1:1 ratio. The amalgam condensation over the RMGIC while on the plastic phase allowed the achievement of a thin layer of RMGIC between the tooth and the restoration, and this technique has also been applied in other studies for evaluation of the marginal microleakage $\mathrm{e}^{21,23,29}$.

The best outcomes observed for the GIII-VT may be the result of some characteristics of the GIC, such as the chemical bonding to the dental structure ${ }^{1,16}$ and hydrophilia, which allow bonding between the GIC and the tooth even in the presence of dentin moisture ${ }^{25}$. An additional good property is the coefficient of linear thermal expansion similar to the dentin ${ }^{1,16}$, however the RMGIC's exhibit a larger discrepancy of this property when compared to the conventional GIC's ${ }^{16}$. It should also be highlighted that, in the case of the RMGIC employed, the application of a light-cured self-etching primer is indicated in order to promote removal of great part of the smear layer, keeping the integrity of the smear plug $^{8}$, what probably contributed to the efficient sealing of the dentinal tubules in this group. This system provides a simultaneous action of the acid etching and penetration of the primer ${ }^{14}$, also assuring a micromechanic union between the material and the dental structure.

The dye penetration may be classified in a qualitative manner, by means of scores, or in a quantitative manner through linear measurements. The first method is the most widely employed, however the quantitative methods provide the extension of dye penetration more accurately ${ }^{19}$. This evaluation may be done through microscopy ${ }^{19,21}$ or by means of digitized image ${ }^{29}$ with utilization of softwares. However, these usually present shadows and image distortions.

Table 1 demonstrates that the means obtained by the microscope were always larger than those achieved by the SUL, with statistically significant differences between the three study groups, what probably occurred because of the higher sensitivity of the first method. When the results of the microscope and the SSL were compared, there was a significant difference just for GIII-VT. Comparing the data achieved by the methods employing the software, a statistically significant difference was observed just for GICP and GII-OS, which exhibited more dye penetration at the axial wall. This increased the means on the evaluation by the SSL, which also evaluated the marginal microleakage at this wall and revealed results similar to those of the microscope and distant from those achieved by the SUL. The GIII-VT showed the lower results, and no specimen presented dye penetration at the axial wall. Therefore, the results obtained by the SUL and SSL in this group were quite similar and statistically inferior to those achieved by the microscope.

Despite of the statistically significant differences, the three methods presented a strong positive correlation, demonstrating that the results reflected a similar performance for each lining materials analyzed. This is an interesting finding, since the microscope is a more expensive equipment and the evolution and popularity of electronic equipments provides another option that may be employed for the accomplishment of this type of study.

Our results agrees with the data reported on in vitro studies, since no material was able to eliminate the marginal microleakage and the best results were obtained with the application of adhesive materials. It is extremely important that new materials and techniques be comprehensively tested and evaluated in vitro before they are clinically applied. Scientifically controlled longitudinal in vivo studies are still required to verify if the adhesive materials should really replace the cavity varnish, taking into account that the operative technique becomes longer and more sensitive, what significantly influences the pediatric dental treatment. In addition, the few in vivo studies ${ }^{3,20}$ conducted have reported little advantage of this type of restoration in relation to the conventional techniques.

\section{CONCLUSION}

Analysis of the results achieved under the present experimental conditions allowed the conclusion that none of the three restorative systems was able to eliminate the marginal microleakage, having the adhesive materials presented similar performances to each other and superior performance when compared to the cavity varnish. The evaluation methods studied demonstrated to yield reliable results.

\section{ACKNOWLEDGMENTS}

The authors thank FAPESP for the support to this research (process 98/06794-7).

\section{REFERENCES}

1- Aboush YEY, Elderton RJ. Bonding dental amalgam to a lightcuring glass-ionomer liner/base. Br Dent J 1991;170(23):219-22.

2- Al-Moayad M, Aboush YEY, Elderton RJ. Bonded amalgam restorations: a comparative study of glass-ionomer and resin adhesives. Br Dent J 1993;175(10):363-7. 
3- Belcher MA, Stewart GP. Two-year clinical evaluation of an amalgam adhesive. J Am Dent Assoc 1997;128(3):309-15.

4- Ben-Amar A, Cardash HS, Judes H. The sealing of the tooth/ amalgam interface by corrosion products. J Oral Rehabil 1995;22(2):101-4.

5- Ben-Amar A, Liberman R, Judes H, Nordenberg D. Long-term use of dentin adhesive as an interfacial sealer under class II amalgam restorations. J Oral Rehabil 1990; 17(1):37-42.

6- Berry TG, Tjan AHL. Microleakage of amalgam restorations lined with dentin adhesives. Am J Dent 1994;7(6): 333-5.

7- Carvalho RM. Adesivos dentinários - fundamentos para aplicação clínica. Rev Dent Rest 1998;1(2):62-96.

8- Friedl K, Powers JM, Hiller KA. Influence of different factors on bond strength of hybrid ionomers. Oper Dent 1995;20(2):74-80.

9- Kidd EA. Microleakage: a review. J Dent 1976;4(5):199-206.

10- Kilpatrick NM. Durability of restorations in primary molars. J Dent 1993;21(1):67-73.

11- Korale ME, Meiers JC. Microleakage of dentin bonding systems used with spherical and admixed amalgams. Am J Dent 1996; 9(6):24952.

12- Kulapongs KJ, Moore BK, Cochran MA. Microleakage of resinlined amalgams using confocal microscopy and fluorescent markers. J Dent Res 1998;77:243.

13- Mahler DB. The amalgam-tooth interface. Oper Dent 1996; 21(6):230-6.

14- Miyazaki M, Sato M, Onose H. Durability of enamel bond strength of simplified bonding systems. Oper Dent 2000; 25(2):7580 .

15- Myaki SI, Rodrigues CR, Raggio DP, Flores TA, Matson M.R. Microleakage in primary teeth restored by conventional or bonded amalgam technique. Braz Dent J 2001;12(3):197-200.

16- Navarro MFL, Pascotto R. Cimentos de ionômero de vidro. São Paulo: Artes Médicas; 1998.

17- Neme AL, Evans, DB, Maxson, BB. Evaluation of dental adhesive systems with amalgam and resin composite restorations: comparison of microleakage and bond strenght results. Oper Dent 2000;25(6):5129 .

18- Ng BP, Purton DG, Hood JAA. Effects of lining materials on shear bond strength of amalgam and galliun alloy restorations. Oper Dent 1998;23(3):113-20.

19- Oliveira FS, Silva, SMB, Bijella, MFTB, Lima, JEO. In vitro evaluation of the marginal microleakage of class II amalgam restoration associated with dentin adhesive. Rev odontol Univ São Paulo 1999;13(3):263-8.

20- Ölmez A, Cula S, Ulusu T. Clinical evaluation and marginal leakage of Amalgambond plus: three-year results. Quintessence Int 1997;28(10):651-6.

21- Pereira Júnior ES, Bijella MFTB, Silva SMB, Vono BG. In vitro evaluation of marginal microleakage of class II bonded amalgam restorations using a dentin adhesive and glass ionomer cement. Rev odontol Univ São Paulo 1999; 13(2):103-9.

22- Phillips RW. Ligas para amálgama dentário e estrutura do amálgama. In: Materiais dentários de Skinner. Rio de Janeiro: Interamericana; 1984. p.219-41.
23- Pinto MB. Avaliação da infiltração marginal em restaurações com amálgama utilizando como materias intermediários verniz cavitário e diferentes sistemas adesivos. Bauru; 1997. [Dissertação de Mestrado - Faculdade de Odontologia de Bauru da USP].

24- Powell GL, Daines DT. Solubility of a cavity varnish: a study in vitro. Oper Dent 1987;12(2):48-52.

25- Prati C, Pashley DH, Montanari G. Hydrostatic intrapulpal pressure and bond strength of bonding systems. Dent Mater 1991;7(1):54-8.

26- Roulet JF. Benefits and disadvantages of tooth-coloured alternatives to amalgam. J Dent 1997;25(6):459-73.

27- Royse MC, Ott NW, Mathieu GP. Dentin adhesive superior to copal varnish in preventing microleakage in primary teeth. Pediatr Dent 1996;18(7):440-3.

28- Varga J, Matsumura H, Masuhara E. Bonding of amalgam filling to tooth cavity with adhesive resin. Dent Mater 1986;5(2):158-64.

29- Youngson CC, Grey NJA, Glyn Jones J. In vitro marginal microleakage: examination of measurements used in assessment. J Dent 1990;18(3):142-6. 